\title{
Metabolisable energy consumption in the exclusively breast-fed infant aged 3-6 months from the developed world: a systematic review
}

\author{
John J. Reilly ${ }^{1}$, Susan Ashworth ${ }^{2}$ and Jonathan C. K. Wells ${ }^{3}$ \\ ${ }^{1}$ University of Glasgow Division of Developmental Medicine, Yorkhill Hospitals, Glasgow G3 8SJ, UK \\ ${ }^{2}$ University of Glasgow Library, Hillhead Street, Glasgow G12 8QQ, UK \\ ${ }^{3}$ MRC Childhood Nutrition Research Centre, Institute of Child Health, University College London, 30 Guilford Street, London WC1N \\ $1 E H, U K$
}

(Received 27 October 2004 - Revised 31 January 2005 - Accepted 8 February 2005)

\begin{abstract}
The present study aimed to evaluate evidence on metabolisable energy consumption and pattern of consumption with age in infants in the developed world who were exclusively breast-fed, at around the time of introducing complementary feeding. We carried out a systematic review aimed at answering three questions: how much milk is transferred from mother to infant?; does transfer increase with the age of the infant?; and what is the metabolisable energy content of breast milk? Thirty-three eligible studies of 1041 mother-infant pairs reported transfer at 3-4 months of age, the weighted mean transfer being 779 (SD 40) g/d. Six studies (99 pairs) measured transfer at 5 months, with a weighted mean transfer of 827 (SD 39 ) g/d. Five studies (72 pairs) measured milk transfer at 6 months, reporting a weighted mean transfer of 894 (SD 87) g/d. Nine longitudinal studies reported no significant increases in milk transfer after 2-4 months. Twenty-five studies on breast-milk energy content were based on 777 mother-infant pairs. The weighted mean metabolisable energy content was 2.6 (SD 0.2$) \mathrm{kJ} / \mathrm{g}$. Breast-milk metabolisable energy content is probably lower, and breast-milk transfer slightly higher, than is usually assumed. Longitudinal studies do not support the hypothesis that breast-milk transfer increases markedly with age. More research on energy intake in 5-6-month-old exclusively breast-fed infants is necessary, and information on the metabolisability of breast milk in mid-infancy is desirable. This evidence should inform future recommendations on infant feeding and help to identify research needs in infant energy balance.
\end{abstract}

Infant nutrition: Breast feeding: Complementary feeding: Energy metabolism

The evidence base for many infant-feeding recommendations is currently limited (Michaelsen et al. 2000; Lanigan et al. 2001; Kramer \& Kakuma, 2002). For example, a review on the possible adequacy of breast milk to meet energy and nutrient requirements up to the age of 6 months noted a lack of published evidence on infant energy intake with which to address this question and called for further research (Butte et al. 2002). We were also aware that many implicit but important assumptions (about breast-milk transfer, metabolisability and energy content, for example) have commonly been made in the literature, and these assumptions have been repeated and widely used in infant-feeding recommendations. The assumptions have not generally been formally tested, and it is widely recognised that more evidencebased approaches to the issue would be helpful (Michaelsen et al. 2000; Lanigan et al. 2001; Kramer \& Kakuma, 2002).

Before embarking on a new research project on energy balance in infancy, we had the opportunity to test the evidence base on critical energy-balance variables by conducting a systematic review of studies on exclusively breast-fed infants over the period when complementary feeding is usually introduced. 'Exclusive breast-feeding' is defined in WHO terms as feeding exclusively with breast milk (World Health Organization, 1995), with no other liquids or solids. 'Complementary feeding' is defined by the WHO as the feeding of any nutrient-containing foods or liquids other than breast milk (Brown et al. 1998), and 'weaning' is defined by the WHO as the complete cessation of breast-feeding (Brown et al. 1998). The recent review, by Butte et al. (2002), on the adequacy of breast milk during exclusive breast-feeding included studies of infants receiving complementary foods/liquids and assumed a value for energy content of breast milk. In the present review, we wanted to focus on the exclusively breast-fed infant in order to examine the evidence on the energy content of breast milk in greater detail, and to estimate metabolisable rather than gross energy intake.

The specific aims of the present review were systematically to extract and summarise evidence on three questions:

1. How much milk is transferred from mother to infant?

2. Does milk transfer increase to match the increasing energy needs of the infant in longitudinal studies?

3. What is the metabolisable energy content of the breast milk transferred?
Methods
Search strategy
We searched for observational studies in Medline, Embase and the Cochrane Library up to the end of 2002. Details of the search strat- egy used, the studies obtained, the numbers and the reasons for inclusion and exclusion are described and summarised in Table 1. 
Table 1. Checklist for reporting of systematic reviews, following the Meta-analysis of Observational Studies in Epidemiology statement (Stroup et al. 2000)

\begin{tabular}{|c|c|}
\hline $\begin{array}{l}\text { Background - definition of the problem } \\
\text { Search strategy }\end{array}$ & $\begin{array}{l}\text { Recent recommendations on infant feeding have concluded that the evidence base for recommendations is limited } \\
\text { Searched Medline, Embase, Cochrane from inception until end of } 2002 \\
\text { Searching of all identified WHO reviews on this topic (J. R.) } \\
\text { Search carried out by specialist biomedical sciences librarian (S. A.) } \\
\text { Hand-searching of reference lists from all potentially relevant papers (J. R.) } \\
\text { Searched for papers only in English (appropriate given the inclusion criteria) } \\
\text { Contact with key authors; presentation of the review protocol at a UK meeting on the evidence base for } \\
\text { infant-feeding recommendations }\end{array}$ \\
\hline Inclusion/exclusion criteria & $\begin{array}{l}\text { Excluded studies with manipulation of infant or mother; studies outside the geographical areas noted above; multiple } \\
\text { births; infants not described as being exclusively breast-fed; infants }<3 \text { or }>6 \text { months of age; infants who } \\
\text { were ill or pre-term; duplicate publications; studies using test-weighing of mothers } \\
\text { Numbers included/excluded for: breast-milk output (rejected } 188 \text { publications, included forty-four); breast-milk } \\
\text { energy content (rejected 145, included twenty-five); longitudinal studies of milk transfer (identified nine). } \\
\text { Further details available from the corresponding author }\end{array}$ \\
\hline Methods & $\begin{array}{l}\text { Assessment of study quality-only studies that used valid methods were included: for milk transfer, this meant } \\
\text { test-weighing of babies and isotopic methods; for milk energy content, studies that used analysis of sampled } \\
\text { milk or isotopic methods were included } \\
\text { Methods available for the measurement of all three variables (breast-milk output, breast milk energy content) are } \\
\text { accurate and precise } \\
\text { No formal assessment of quality of included studies in light of the above; problems in assessing quality of } \\
\text { observational studies } \\
\text { Data extracted by authors using pre-piloted form }\end{array}$ \\
\hline Sensitivity/sub-group analyses & $\begin{array}{l}\text { Planned analysis based on methodological differences between studies. For studies of breast-milk output, we } \\
\text { compared test-weighing } v \text {. the isotopic method. For breast-milk energy content, we compared the isotopic } \\
\text { method } v \text {. milk-sampling procedures. For breast-milk energy content, we compared different } \\
\text { sampling schedules } \\
\text { Calculated pooled data with and without inclusion of outliers } \\
\text { These analyses produced estimates of milk transfer and milk energy content that were similar } \\
\text { Formally tested for heterogeneity between studies }\end{array}$ \\
\hline Results & $\begin{array}{l}\text { Gave results of individual studies (in tables) and group estimates } \\
\text { Provided essential details of methodology and sample for each study included } \\
\text { Gave results of subgroup/sensitivity analyses } \\
\text { Considered impact of bias in individual studies to be negligible in view of the nature of the questions addressed and } \\
\text { lack of bias in the methodology used }\end{array}$ \\
\hline Discussion & $\begin{array}{l}\text { Noted limitations associated with summary measures } \\
\text { Noted need for further research }\end{array}$ \\
\hline
\end{tabular}

We followed the Meta-analysis of Observational Studies in Epidemiology (Stroup et al. 2000) approach as the evidence relevant to our three aims was derived largely from observational studies. 'Cochrane' methodology is generally more appropriate for summarising and appraising the results of interventions, particularly randomised-controlled trials. Further details of individual studies are available from the corresponding author. We cross-checked our search results against studies cited in previous systematic (Lanigan et al. 2001; Kramer \& Kakuma, 2002) and non-systematic (Brown et al. 1998; Michaelsen et al. 2000; Butte et al. 2002) reviews, and also hand-searched every citation identified for other relevant evidence.

\section{A priori inclusion and exclusion criteria - subjects}

We included published evidence on only three topics: breast milk output, within-infant trends in milk consumption from longitudinal studies, and breast-milk energy content. We only included studies of healthy, term, singleton infants between 3 and 6 months old in the developed world (Europe, North America, Australia and New Zealand). Studies from the developing world were excluded for two principal reasons. First, we wanted, for pragmatic reasons, to reduce the workload of the review while maintaining a high degree of focus on our three specific questions (aims). Second, we wanted our review evidence to contribute to the debate on the adequacy of exclusive breast-feeding for 6 months in the developed world, in view of the recent adoption of this recommendation in England and across the developed world.

We included only studies in which infants were described as exclusively breast-fed, and in which this was defined as mothers providing breast milk as the sole source of nutrients and energy. Very few studies specifically referred to WHO definitions of exclusive breast-feeding or complementary feeding, but almost all noted whether nutrients other than breast milk were being consumed. We excluded studies in which infants were described as being partially or predominantly breast-fed. We included only those studies which reported new data and excluded duplicate publications (e.g. in reviews). We also excluded studies of multiple births and studies in which mothers and/or babies were subject to experimental manipulations aimed at altering breast-milk output or composition, such as nutritional supplementation or experimentally scheduled feeding.

\section{A priori inclusion and exclusion criteria - methodology}

For the questions addressed in the review, there are several wellestablished methodologies in common use. We included as many studies as possible, so these used a range of techniques: studies were excluded on methodological grounds only if they used methods that have been shown to be invalid. For studies on breast-milk output, we included evidence obtained both by isotopic techniques and by test-weighing the baby as these methods have no 
significant error if performed properly (Scanlon et al. 2002). For the assessment of changes in breast-milk transfer from mother to baby over time, we included only longitudinal studies.

Estimates of breast-milk energy content can be made by sampling breast milk or by carrying out a more physiological study of infant energy balance (Lucas et al. 1987); again, both methods should provide accurate group mean estimates (Scanlon et al. 2002). The breast-milk sampling regime is potentially important as there is diurnal variation in composition and also variation within a feed between fore- and hind-milk (Mitoulas et al. 2002). We aimed to include all eligible studies of breast-milk composition and did not exclude studies based on sampling regime, although differences by method of sampling were considered statistically.

Our initial review of evidence for the present study revealed that most previous studies had estimated the gross energy content of breast milk. In these studies, the gross energy content of the milk was obtained either by bomb calorimetry on the milk sample or by carrying out chemical analysis and then using standard values for the gross energy content of the constituents of milk (protein, fat and carbohydrate; Southgate \& Durnin, 1970). Not all of the gross energy in the milk is available to infants, mainly owing to energy losses in the faeces and urine. Values in most previous studies therefore do not reflect metabolisable energy intake and must systematically overestimate the energy available to infants from breast milk. In contrast, isotopic studies do estimate metabolisable energy content of breast milk, and do so very accurately (Lucas et al. 1987). The primary literature therefore contains a few studies of metabolisable energy content and many studies that report the gross energy content of breast milk. We included evidence from both types of study and have presented both gross and metabolisable energy intake estimates in the present review. Because our primary aim was to establish the metabolisable energy content of breast milk and to minimise the systematic error in intake estimates when gross energy is used, we corrected published estimates of gross energy content where necessary; the method for doing this is described in the following section.

\section{Corrections made to published evidence}

Several corrections to published estimates were necessary. Published estimates of breast-milk transfer that used test-weighing often failed to correct for the insensible water losses that the baby experienced during feeding. This omission typically introduces a systematic underestimation of approximately $2-3 \%$ in breastmilk transfer (Butte et al. 1990; Neville et al. 1988). The precise magnitude of the error will of course vary, but in the present review we corrected where the published values did not take insensible losses into account. We did so in order to produce estimates of metabolisable energy content that were unbiased, or at least less biased than those available from the primary literature. We therefore adjusted published estimates where necessary by increasing them by $5 \%$ as a conservative approach to correcting for this error. Many published estimates of breast-milk energy transfer or energy content presented data volumetrically $(\mathrm{ml} / \mathrm{d}$ or $\mathrm{kcal} / \mathrm{ml})$, and we have corrected these to $\mathrm{g} / \mathrm{d}$ using a correction for the density of milk of $1.03 \mathrm{~g} / \mathrm{ml}$ (Neville et al. 1988) as this is also a source of systematic error that should be reduced when attempting to estimate the daily energy intake of infants.

Our search for empirical evidence on the metabolisability of breast milk found only a single energy-balance study (Southgate
\& Barrett, 1966); this suggested that an average of $92 \%$ of the gross energy in breast milk was available to the infant. This study was, however, carried out on 14-d-old infants, and the average efficiency of digestion and absorption shows a marginal increase later in infancy (Zoppi et al. 1972; Manson \& Weaver, 1997). In adults, the use of the modified Atwater factors is a generally valid means of correcting gross energy to metabolisable energy (Southgate \& Durnin, 1970), with group mean estimates of metabolisability of 90-93\% of gross energy for adults on typical Western diets, and a metabolisability of approximately $96 \%$ for milk. The applicability of this evidence to breast-fed infants is questionable, but in view of the single study in infants, we corrected published estimates of the gross energy content of breast milk to metabolisable energy content by assuming that, on average, $93 \%$ of breast-milk energy is metabolisable. We have presented both gross and metabolisable intake estimates in the present review.

\section{Results}

How much milk is transferred?: evidence on breast-milk transfer

Our literature search identified 232 potentially eligible papers. We screened these for eligibility, and forty-four were included.

Infants 3-4 months old. We identified thirty-three eligible studies with a total sample of 1041 mother-infant pairs (Table 2). The weighted mean milk transfer was 779 (SD 40) g/d, and the unweighted mean was 796 (SD 48) g/d (95\% CI 778, $812 \mathrm{~g} / \mathrm{d}$ ).

Infants 5 and 6 months old. We identified six eligible studies of infants described as being 5 months old, with ninety-nine mother-infant pairs in total (Table 3). Weighted mean milk transfer was 826 (SD 39) g/d. The unweighted mean was 816 (SD 42) g/d (95\% CI 772, $860 \mathrm{~g} / \mathrm{d})$.

We identified five eligible studies of seventy-two mother-infant pairs with the infants described as being 6 months old (Table 3). Weighted mean milk transfer was 894 (SD 87) g/d and unweighted mean transfer 883 (SD 89) g/d (95\% CI 790, $975 \mathrm{~g} / \mathrm{d})$.

Sensitivity analysis - differences in milk transfer by method of measurement. We carried out a planned sub-group analysis that compared the three studies ( $n 43$ mother-infant pairs), which employed isotopic methods with the thirty-eight studies ( $n 1146$ mother-infant pairs) that used the alternative method of testweighing the babies. Mean estimated milk transfer by the thirtyeight studies that used test-weighing was 799 (SD 47) g/d, and by the three studies that used the isotopic method mean milk transfer was 864 (SD 63) g/d. Differences in milk transfer by method were significant $(P=0.02)$, with significantly higher estimates from the three studies that used isotopic methods (mean difference $66 \mathrm{~g} / \mathrm{d}$; $95 \% \mathrm{CI}$ for difference $11,123 \mathrm{~g} / \mathrm{d}$ ). Visual examination of the forty-one individual studies for outliers suggested two that had a relatively low estimated milk transfer, but the inclusion or exclusion of these studies had a negligible effect $(<5 \mathrm{~g} / \mathrm{d})$ on the overall mean milk transfer estimates.

Does milk transfer increase to compensate for increasing infant energy needs?: evidence from longitudinal studies on changes in breast-milk transfer

We identified nine longitudinal studies in which measurements of breast-milk transfer had been made at least twice in the same exclusively breast-fed infant between the periods of 2 and 5 months of age 
Table 2. Studies on exclusively breast-fed infants 3-4 months old: milk transfer (Italics denotes longitudinal study)

\begin{tabular}{|c|c|c|c|c|c|}
\hline Study & $n$ & Age (months) & Mean $(g / d)$ & SD & Method \\
\hline Lonnerdal et al. (1976) & 12 & $3 \cdot 5-4 \cdot 0$ & 810 & 154 & TW \\
\hline Whitehead \& Paul (1981) & 32 & $3-4$ & 839 & 160 & TW \\
\hline Pao et al. (1980) & 2 & 3 & 892 & 170 & TW \\
\hline Whitehead et al. (1981) & 6 & 4 & 823 & 97 & TW \\
\hline Chandra (1981) & 33 & 3 & 825 & - & TW \\
\hline Hofvander et al. (1982) & 25 & $3-4$ & 807 & - & TW \\
\hline Picciano et al. (1981) & 16 & $3-4$ & 662 & 124 & TW \\
\hline Kohler et al. (1984) & 21 & $3-4$ & 755 & 148 & TW \\
\hline World Health Organization (1985) & 28 & $3-4$ & 807 & 99 & TW \\
\hline Dewey \& Lonnerdal (1983) & 16 & $3-4$ & 827 & 181 & TW \\
\hline Butte \& Garza (1985) & 41 & 4 & 770 & 133 & TW \\
\hline Butte (1986) & 43 & $3-4$ & 762 & 93 & TW \\
\hline Prentice et al. (1986) & 47 & $3-4$ & 814 & 183 & TW \\
\hline Dewey (1986) & 53 & $3-4$ & 749 & 142 & TW \\
\hline Paul et al. (1988) longitudinal & 47 & $3-4$ & 798 & 159 & TW \\
\hline Dewey \& Lonnerdal (1986) longitudinal & 18 & $3-4$ & 761 & 115 & TW \\
\hline Lucas et al. (1987) & 12 & 3 & 896 & 41 & Isotopic \\
\hline Butte et al. (1990) & 15 & 4 & 776 & 119 & TW \\
\hline Nommsen et al. (1991) & 58 & $3-4$ & 811 & 133 & TW \\
\hline van Raaij et al. (1991) longitudinal & 16 & 3 & 775 & 184 & TW \\
\hline Butte et al. (1991) & 111 & 4 & 785 & 129 & TW \\
\hline Goldberg et al. (1991) & 10 & 3 & 792 & 177 & Isotopic \\
\hline Dewey et al. (1990) & 73 & $3-4$ & 812 & 133 & TW \\
\hline Butte et al. (1990) & 10 & $3-4$ & 770 & 104 & TW \\
\hline Wells (1994) & 21 & 3 & 905 & 125 & Isotopic \\
\hline Lovelady et al. (1993) & 9 & 4 & 800 & 95 & TW \\
\hline Krebs et al. (1994) & 71 & $3-4$ & 718 & 114 & TW \\
\hline de Bruin et al. (1998) & 23 & 4 & 763 & 120 & TW \\
\hline Butte et al. (2000) & 40 & $3-4$ & 780 & 168 & TW \\
\hline Butte et al. (2001) & 24 & $3-4$ & 763 & 144 & TW \\
\hline Matheny \& Picciano (1985) & 18 & 3 & 756 & 141 & TW \\
\hline Heinig et al. (1993) & 71 & 3 & 812 & 133 & TW \\
\hline Stuff \& Nichols (1989) & 19 & 4 & 832 & 117 & TW \\
\hline Weighted mean & & & 796 & & \\
\hline
\end{tabular}

TW, test-weighing.

Where breast milk transfer was not corrected for insensible water loss, estimates of transfer have been increased by $5 \%$.

(Butte et al. 1984; Dewey \& Lonnerdal, 1986; Neville et al. 1988; Paul et al. 1988; Wood et al. 1988; van Raaij et al. 1991; Michaelsen et al. 1994; Motil et al. 1997; Mitoulas et al. 2002). Periods of measurement varied, but typically extended from age $2-4$ or $2-5$ months. All nine studies reported no marked increase in milk transfer over the periods of time measured, and most described the pattern of change in intake over time as a 'plateau' in milk transfer after 3 months.

What is the metabolisable energy content of breast milk?: empirical evidence on breast-milk energy content

Of the 170 potentially eligible papers identified by our literature search, twenty-five met our entry criteria, and these had a pooled sample size of 777 mother-infant pairs. These studies are summarised in Table 4 . The weighted mean metabolisable energy content of milk was $2.6(\mathrm{SD} 0 \cdot 2) \mathrm{kJ} / \mathrm{g}$ (equivalent to $0.62 \mathrm{kcal} / \mathrm{g}$ ).

Sensitivity analysis: differences in milk energy content by method and by milk sampling regime. Differences in the estimated metabolisable milk energy content associated with the method of measurement (isotopic methods in two studies $v$. milk sampling in the remaining twenty-three) were not significant $(P=0 \cdot 16)$. Visual inspection of the twenty-five studies suggested that four were possible outliers. The inclusion or exclusion of these four possible outliers, three of which observed low estimates of energy density and one of which produced a high estimate, had a negligible effect on the overall estimate of energy density. The unweighted mean milk energy content from all the studies was

Table 3. Studies on exclusively breast-fed infants 5 and 6 months old: milk transfer (Italics denotes longitudinal study)

\begin{tabular}{lrrrr}
\hline & \multicolumn{5}{c}{$\begin{array}{c}\text { Mean } \\
\text { Study }\end{array}$} & $n$ & $(\mathrm{~g} / \mathrm{d})$ & SD & Method \\
\hline 5-month-old infants & & & & \\
$\quad$ Neville et al. (1988) longitudinal & 13 & 875 & 122 & TW \\
Stuff et al. (1986) & 9 & 764 & 88 & TW \\
Neville \& Rasbach (1988) & 12 & 790 & 75 & TW \\
Wood et al. (1988) longitudinal & 19 & 847 & 209 & TW \\
Michaelsen et al. (1994) longitudinal & 35 & 831 & 138 & TW \\
Motil et al. (1997) longitudinal & 10 & 788 & 225 & TW \\
Weighted mean & & 827 & & \\
6-month-old infants & & & & \\
Salmenpera et al. (1985) & 31 & 857 & 129 & TW \\
Chandra (1981) & 27 & 982 & 136 & TW \\
Pao et al. (1980) & 1 & 737 & - & TW \\
Stuff \& Nichols (1989) & 8 & 859 & 174 & TW \\
Whitehead et al. (1981) & 1 boy & 996 & - & TW \\
Whitehead et al. (1981) & 4 girls & 905 & 95 & TW \\
Weighted mean & & 894 & & \\
\hline
\end{tabular}

TW, test-weighing. 
Table 4. Energy content of breast milk

\begin{tabular}{|c|c|c|c|c|c|c|}
\hline Study & $n$ & $\begin{array}{c}\text { Mean energy content } \\
\text { as reported }(\mathrm{KJ} / \mathrm{g})\end{array}$ & SD & Method* & $\begin{array}{c}\text { Gross energy (GE) or } \\
\text { estimated metabolisable (eME) } \\
\text { or metabolisable (ME) energy }\end{array}$ & $\begin{array}{l}\text { Corrected metabolisable } \\
\text { energy content } \\
(\mathrm{GE} \times 0.93)\end{array}$ \\
\hline Dewey \& Lonnerdal (1983) & 16 & 3.0 & 0.6 & $\mathrm{~S}, \mathrm{a}$ & GE & $2 \cdot 8$ \\
\hline Butte et al. (1984) & 41 & $2 \cdot 7$ & 0.4 & $\mathrm{~S}, 24 \mathrm{~h}$ & GE & $2 \cdot 5$ \\
\hline World Health Organization (1985) & 28 & $3 \cdot 2$ & 0.9 & $\mathrm{~S}, \mathrm{u}$ & GE & 3.0 \\
\hline World Health Organization (1985) & 83 & $2 \cdot 5$ & 0.4 & $\mathrm{~S}, \mathrm{u}$ & GE & $2 \cdot 4$ \\
\hline Lucas et al. (1987) & 12 & $2 \cdot 5$ & 0.2 & 1 & $\mathrm{ME}$ & 2.5 \\
\hline Wood et al. (1988) & 15 & $2 \cdot 3$ & 0.2 & $\mathrm{~S}, 24 \mathrm{~h}$ & GE & $2 \cdot 2$ \\
\hline Butte et al. (1990) & 10 & $2 \cdot 6$ & 0.3 & $\mathrm{~S}, 24 \mathrm{~h}$ & GE & $2 \cdot 4$ \\
\hline Stuff \& Nichols (1989) & 19 & $2 \cdot 6$ & - & $\mathrm{S}, 24 \mathrm{~h}$ & GE & 2.5 \\
\hline Dewey et al. (1990) & 73 & $2 \cdot 9$ & 0.3 & $\mathrm{~S}, 24 \mathrm{~h}$ & GE & $2 \cdot 8$ \\
\hline Nommsen et al. (1991) & 58 & $2 \cdot 8$ & 0.3 & $\mathrm{~S}, 24 \mathrm{~h}$ & GE & $2 \cdot 7$ \\
\hline Butte et al. (1991) & 111 & $2 \cdot 7$ & 0.5 & $\mathrm{~S}, 24 \mathrm{~h}$ & GE & $2 \cdot 5$ \\
\hline Lovelady et al. (1993) & 9 & $2 \cdot 8$ & 0.4 & $\mathrm{~S}, 24 \mathrm{~h}$ & GE & $2 \cdot 6$ \\
\hline Michaelsen et al. (1994) & 35 & 2.9 & 0.4 & S, a & GE & $2 \cdot 7$ \\
\hline Heinig et al. (1993) & 71 & $2 \cdot 8$ & - & $\mathrm{S}, 24 \mathrm{~h}$ & GE & $2 \cdot 5$ \\
\hline Motil et al. (1997) & 10 & 3.0 & 0.3 & $\mathrm{~S}, 24 \mathrm{~h}$ & GE & $2 \cdot 8$ \\
\hline de Bruin et al. (1998) & 23 & $2 \cdot 4$ & 0.4 & $\mathrm{~S}, 24 \mathrm{~h}$ & GE & $2 \cdot 2$ \\
\hline Butte et al. (2000) & 40 & $2 \cdot 7$ & 0.4 & $\mathrm{~S}, 24 \mathrm{~h}$ & GE & 2.5 \\
\hline Butte et al. (2001) & 24 & $2 \cdot 7$ & 0.3 & $\mathrm{~S}, 24 \mathrm{~h}$ & GE & $2 \cdot 5$ \\
\hline Mitoulas et al. (2002) & 16 & 2.5 & 0.6 & S, o & GE & $2 \cdot 3$ \\
\hline Sadurskis et al. (1988) & 23 & $2 \cdot 7$ & 0.3 & $\mathrm{~S}, 24 \mathrm{~h}$ & GE & 2.5 \\
\hline Lepage et al. (1984) & 11 & $2 \cdot 7$ & 0.1 & $\mathrm{~S}, 24 \mathrm{~h}$ & GE & $2 \cdot 5$ \\
\hline Garza et al. (1983) & 4 & $2 \cdot 3$ & 0.2 & S, a & GE & $2 \cdot 1$ \\
\hline Garza \& Butte (1986) & 10 & 3.0 & 0.5 & $\mathrm{~S}, 24 \mathrm{~h}$ & GE & $2 \cdot 8$ \\
\hline
\end{tabular}

* Methods used various forms of milk sampling (S) or an isotopic method (I). Sampling studies used $24 \mathrm{~h}$ sampling periods (, $24 \mathrm{~h}$ ), abbreviated sampling schedules ( $\mathrm{S}$, a), more complex schedules $(\mathrm{S}, \mathrm{o})$ or schedules that were unclear from the methodological descriptions provided $(\mathrm{S}, \mathrm{u})$. In most studies, the GE content of breast milk was calculated from either bomb calorimetry or values for the gross energy content of the chemical constituents. Values denoted as 'eME' used corrections to estimate the metabolisable energy content of breast milk. 'ME' indicates values calculated in comprehensive studies of the infant energy budget using isotopic methods. In all studies that reported gross energy content, this was corrected to metabolisable energy content by reducing the values by $7 \%$.

$2 \cdot 5(\mathrm{SD} 0 \cdot 2) \mathrm{kJ} / \mathrm{g}(95 \% \mathrm{CI} 2 \cdot 4,2 \cdot 6 \mathrm{~kJ} / \mathrm{g})$, which is equivalent to 0.61 (SD 0.05$) \mathrm{kcal} / \mathrm{g}(95 \%$ CI $0.59,0.63 \mathrm{kcal} / \mathrm{g})$.

We considered the possibility that milk energy content might vary by sampling regime, in particular differences between studies that used $24 \mathrm{~h}$ samples and those which employed shorter sampling regimes. Of the twenty-five eligible studies identified most (fifteen) used $24 \mathrm{~h}$ sampling (mean 2.5 (SD $0 \cdot 2$ ) kJ/g, $95 \%$ CI $2.4,2.6 \mathrm{~kJ} / \mathrm{g}$ ), five used abbreviated sampling schedules (mean 2.5 (SD 0.2 ) $\mathrm{kJ} / \mathrm{g}, 95 \%$ CI $2.2,2.8 \mathrm{~kJ} / \mathrm{g}$; equivalent to 0.62 (SD 0.06) kcal $/ \mathrm{g}, 95 \%$ CI $0.54,0.70 \mathrm{kcal} / \mathrm{g}$ ), two did not describe the sampling regime in sufficient detail (mean $2.4 \mathrm{~kJ} /$ g), one used a complex sampling regime that aimed to obtain representative samples $(2.3 \mathrm{~kJ} / \mathrm{g})$, and two studies estimated metabolisable energy content from isotopic methods (mean $2 \cdot 4 \mathrm{~kJ} / \mathrm{g}$ ).

Differences in milk-energy content between studies could also have arisen because of a variation in milk composition within a feed, as marked differences in the composition of fore- and hind-milk are well known. We considered this possibility in our sensitivity analysis for the twenty-three studies that used milk sampling. Fourteen of the twenty-three studies attempted to take account of this source of variation by complete evacuation of the breast during sampling (mean estimated metabolisable energy content 2.5 (SD 0.2$) \mathrm{kJ} / \mathrm{g}$,), five studies did not describe their approach to dealing with this problem (mean estimated metabolisable energy content 2.6 (SD 0.3$) \mathrm{kJ} / \mathrm{g}$ ), and two used complex sampling regimes to take account of differences between fore- and hind-milk (mean estimated metabolisable energy content for these two studies $2.5 \mathrm{~kJ} / \mathrm{g}$ ).

\section{Discussion}

Main findings

In answer to our original three questions (aims), we found in the present study that:

- cross-sectional studies of milk transfer suggest that it typically varies between approximately $779 \mathrm{~g} / \mathrm{d}$ at age $3-4$ months (for which there was a great deal of evidence: thirty-three studies of 1041 mother-infant pairs) and approximately $894 \mathrm{~g} / \mathrm{d}$ at age 6 months (for which evidence was limited: five studies with seventy-two possibly highly selected mother-infant pairs);

- longitudinal studies, in contrast, did not suggest any marked increase in milk transfer over time over the period 3-6 months. The metabolisable energy content of breast milk is approximately $2 \cdot 6 \mathrm{~kJ} / \mathrm{g}$.

\section{Context and comparisons with other evidence}

We believe that the present study is important in that it takes a critical, quantitative and evidence-based approach to the assessment of energy intake during infancy. Other approaches to estimating energy intake in the exclusively breast-fed infant have been important and influential but have tended to use values for energy intake (breast-milk transfer and/or breast-milk energy content) that differ somewhat from the values we have obtained by systematic review, and which in many cases have been based on implicit assumptions that have not been tested against the 
empirical evidence. Whitehead \& Paul (2000), for example, used the widely cited and assumed value for breast-milk energy content of $0.68 \mathrm{kcal} / \mathrm{g}(2.8 \mathrm{~kJ} / \mathrm{g})$ in order to estimate the long-term adequacy of exclusive breast-feeding to meet infant energy needs, and treated this value as metabolisable energy content. Butte et al. (2000) noted that published studies provided estimates of milk energy content ranging from 0.62 to $0.80 \mathrm{kcal} / \mathrm{g}$, but in their assessment of whether or not the energy needs of infants would be met adequately for up to 6 months of exclusive breast-feeding, they used an assumed value for metabolisable energy content of $0.67 \mathrm{kcal} / \mathrm{g}$. In the present review, we have tried to examine these assumptions by reviewing the empirical evidence, and have produced typical estimates for energy intake variables that are based on the widest body of empirical evidence possible.

Milk energy-content values extracted from the literature in the present study were consistently much lower than the widely cited and assumed values, at about $2.6 \mathrm{~kJ} / \mathrm{g}(0.62 \mathrm{kcal} / \mathrm{g})$. We believe that this is due to a combination of factors. First, there is a heavy dependence, and possibly excessive emphasis, in the literature on a small number of widely cited studies that found a relatively high energy content, for example the World Health Organization (1985) study, which included two samples of subjects, one of which provided milk with a mean gross energy content of $0.77 \mathrm{kcal} / \mathrm{g}$ (the mean gross energy content in the other sample in this WHO study being $0.60 \mathrm{kcal} / \mathrm{g}$ ). Other relatively high estimates for gross energy content that are frequently cited include those of Dewey \& Lonnerdal $(1983 ; 0.71 \mathrm{kcal} / \mathrm{g}$ gross energy), Dewey et al. (1990; $0.70 \mathrm{kcal} / \mathrm{g}$ gross energy) and Michaelsen et al. (1994; $0.69 \mathrm{kcal} / \mathrm{g}$ gross energy). Second, although most previous studies (Table 4) actually estimated the gross energy content of breast milk (from proximate composition or bomb calorimetry), the distinction between gross and metabolisable energy content has been widely ignored, so gross energy values have been treated in infant-feeding calculations and recommendations as metabolisable energy content - the use of metabolisable energy content values of about $2 \cdot 9-3.0 \mathrm{~kJ} / \mathrm{g}$ has been common in the literature on infant-feeding recommendations.

Estimates of quantity of breast-milk transfer obtained by the present review were slightly higher than the values commonly assumed and cited: the present review estimates are based on a wider search for evidence. Accepted values for variables such as breast-milk transfer and energy content are accepted in part because of the repeated citation of values derived from a very few studies. The over-dependence on a few studies, some of which would have suffered from common methodological problems that lead to systematic errors (such as the use of the gross energy content of milk, the treatment of milk volume and milk mass as identical, and the failure to correct milk transfer for insensible water loss) is a limitation that has affected the infant-feeding literature. Systematic review is an alternative approach that is explicitly intended to extract and summarise the maximum possible body of evidence on a particular topic. It is therefore unsurprising that the values obtained by a systematic review that is specifically aimed at establishing metabolisable energy intake might differ significantly from widely accepted values. Other differences between different reviews arise from study inclusion and exclusion criteria. In the present review, for example, we excluded studies in which infants were described as being predominantly breast-fed, but such studies were included in the review by Butte et al. (2002).

\section{Methodology and limitations}

We have attempted to minimise the inherent problems of interpretation in our study design by following recommended practice for the systematic review of observational studies and by using only studies that employed validated methods (Stroup et al. 2000). The methods used in the studies reviewed were not generally prone to large biases (Lucas et al. 1987; Mitoulas et al. 2002; Scanlon et al. 2002), and the direction and magnitude of the biases is well known. Only simple and relatively minor corrections were therefore necessary - for insensible water loss (to calculate milk transfer), metabolisablity of milk (to calculate the energy actually available to the baby) and density of milk. The methodological quality (accuracy) of the studies summarised was generally high. Where differences between studies that were related to methodology were likely, we formally tested for such differences and have provided information on methodology used by each study.

\section{Possible implications}

Our findings have a number of possible implications. One is that the energy content of modern infant formulae may be significantly higher than that of breast milk: modern formula milk is designed to mimic the gross composition of breast milk, but its composition has presumably been based on the assumption that breast-milk energy content was higher than the estimate suggested by our review. Our observations may also contribute to the debate on the adequacy of exclusive breast-feeding. We speculate that using lower values for breast-milk energy content than the $0.67-0.68 \mathrm{kcal} / \mathrm{g}$ used in WHO reviews might alter the apparent adequacy of exclusive breast-feeding to 6 months of age.

\section{Consistency of evidence and research needs}

Given differences in samples, settings and methods, our review produced a large body of surprisingly consistent empirical evidence on milk transfer at age 3-4 months, changes in transfer studied longitudinally, and energy content of breast milk. It is likely that much of the between-study difference in mean estimated milk energy content that we have observed in the literature is due to differences in sampling protocols, but the relatively small number of studies and the predominance of the $24 \mathrm{~h}$ sampling technique in the literature precluded formal analysis. It is worth noting that there was, overall, a similarity between studies, with a relatively narrow CI for the estimates of energy content, but that studies based on shorter milk-sampling schedules produced more variable estimates, as expected (Garza \& Butte, 1986; Mitoulas et al. 2002).

More empirical studies of the metabolisability of breast milk would be desirable as evidence in this important area is lacking. Milk transfer data from older (5-6 month) exclusively breastfed infants are extremely scarce. Butte et al. (2002) also noted this paucity of evidence and made the point that, owing to the high rate of cessation of exclusive breast-feeding, the motherinfant pairs studied when infants were aged 5-6 months are likely to have been highly selected and possibly unusual. These observations point to the need for more evidence on breast-milk consumption by infants aged 5-6 months who are exclusively breastfed. 
Our review deliberately excluded studies from the developing world, but in view of the potential implications of our findings, a similar review of data from the developing world would be timely.

\section{Conclusions}

The present review provides a large body of fairly consistent evidence on energy intake during infancy: breast-milk transfer from mother to baby in the exclusively breast-fed infant, changes in transfer with age, and the metabolisable energy content of breast milk. Evidence on milk transfer in older exclusively breast-fed infants is lacking. In some cases, values derived by comprehensive systematic review were markedly different from values widely quoted and used as the basis of infant-feeding recommendations. Evidence on the metabolisability of breast milk is lacking for infants older than $14 \mathrm{~d}$. The review also suggests that more empirical research is required on energy balance during exclusive breast-feeding in the older (5-6-month-old) infant.

\section{Acknowledgements}

We thank Professor Brian Wharton for his suggestions on the review protocol and for providing some references. Professor Nancy Butte kindly provided the WHO (2002) review and commented on an earlier draft of the manuscript. We are grateful to Professor Carolyn Summerbell and Dr Vicki Whittaker for their advice on the systematic review process and the statistical analysis and interpretation of the data. Mr John McColl also helpfully advised on calculation of the summary statistics. The work was funded by a Caledonian Research Foundation Support Research Fellowship to J. J. R. The funding body was not involved in the process of research other than by funding: it had no role in what was studied in the review, the interpretation of the findings, or publication. The authors have no conflicts of interest to declare.

\section{References}

Brown KH, Dewey KG \& Allen LH (1998) Complementary Feeding of Young Children in Developing Countries: A Review of Current Scientific Knowledge. Geneva: WHO.

Butte NF (1986) Breast milk consumption in infancy. In Human Lactation. II. Maternal and Environmental Factors, pp. 30-41 [M Hamosh and AS Goldman, editors]. New York: Plenum Press.

Butte NF \& Garza C (1985) Energy and protein intakes of exclusively breast fed infants in the first 4 months of life. In Nutritional Needs and Assessment of Normal Growth, pp. 218-232 [M Gracey and F Falkner, editors]. Nestle Workshop Series vol. 7. New York: Raven Press.

Butte NF, Garza C, Smith EO \& Nichols B (1984) Human milk intake and growth in exclusively breast-fed infants. J Pediatr 104, 187-195.

Butte NF, Lopez-Alarcon MG \& Garza C (2002) Nutrient Adequacy of Exclusive Breastfeeding for the Term Infant During the First Six Months of Life. Geneva: WHO.

Butte NF, Wong WW, Ferlic L, Smith EO, Klein PD \& Garza C (1990) Energy expenditure and deposition of breast-fed and formula fed infants during early infancy. Pediatr Res 28, 631-640.

Butte NF, Wong WW, Garza C, Stuff JE, Smith EO, Klein PD \& Nichols BL (1991) Energy requirements of breast-fed infants. J Am Coll Nutr 10, 190-195.

Butte NF, Wong WW \& Hopkinson JM (2001) Energy requirements of lactating women derived from doubly-labelled water and milk energy output. J Nutr 131, 53-58.
Butte NF, Wong WW, Hopkinson JM, Heinz CJ, Mehta NR \& Smith EO (2000) Energy requirements derived from total energy expenditure and energy deposition during the first two years of life. Am J Clin Nutr 72, $1558-1569$.

Chandra RK (1981) Breast-feeding, growth, and morbidity. Nutr Res 1, $25-31$.

de Bruin NC, Degenhart HJ, Gal S, Westerterp KR, Stijnen $\mathrm{T}$ \& Visser HKA (1998) Energy utilisation and growth in breast-fed and formula-fed infants measured prospectively during the first year of life. Am J Clin Nutr 67, 885-896.

Department of Health and Social Security (1977) The Composition of Mature Human Milk. Report on Health and Social Subjects no. 12. London: HMSO.

Dewey KG (1986) Milk consumption of exclusively breast fed infants. In Human Lactation. II. Maternal and Environmental Factors, pp. 47-65 [M Hamosh and AS Goldman, editors]. New York: Plenum Press.

Dewey KG, Heinig MJ, Nommsen LA \& Lonnerdal B (1990) Maternal versus infant factors related to breast-milk intake and residual milk volume. Pediatrics 87, 129-137.

Dewey KG \& Lonnerdal B (1983) Milk and nutrient intakes of breastfed infants from 1-6 months. J Pediatr Gastroenterol Nutr 2, 497-506.

Dewey KG \& Lonnerdal B (1986) Infant self regulation of milk intake. Acta Paediatr 75, 893-898.

Garza C \& Butte NF (1986) Energy concentration of human milk estimated from 24-hour pools and various abbreviated sampling schemes. J Pediatr Gastroenterol Nutr 5, 943-948.

Garza C, Johnson CA, Smith EO \& Nichols B (1983) Changes in the nutrient composition of human milk during gradual weaning. Am J Clin Nutr 37, 61-65.

Goldberg GR, Prentice AM, Coward WA, Davies HL, Murgatroyd PR, Sawyer MB, Ashford JB \& Black AE (1991) Longitudinal assessment of the components of energy balance in well nourished lactating women. Am J Clin Nutr 54, 788-798.

Heinig MJ, Nommsen LA, Peerson JM, Lonnerdal B \& Dewey KG (1993) Energy and protein intakes of breast-fed and formula-fed infants during the first year of life. Am J Clin Nutr 58, 152-161.

Hofvander Y, Hagman U, Hillervik C \& Sjolin S (1982) The amount of milk consumed by 1-3 month old breast-fed or bottle fed infants. Acta Paediatr 73, 40-48.

Kohler L, Meeuwisse G \& Mortensson W (1984) Food intake and growth of infants between 6-26 weeks of age. Acta Paediatr 73, 40-48.

Kramer MS \& Kakuma R (2002) Optimal duration of exclusive breastfeeding (Cochrane Review). In The Cochrane Library, Issue 1, Oxford: Update Software.

Krebs NF, Reidinger CJ, Robertson AD \& Hambidge KM (1994) Growth and intakes of energy and zinc in infants fed human milk. J Pediatr 124, 32-39.

Lanigan JA, Bishop JA, Kimber AC \& Morgan J (2001) Systematic review concerning the age of introduction of complementary foods to the healthy full term infant. Eur J Clin Nutr 55, 309-320.

Lepage G, Collet S, Bougle D, Kien LC, Lepage D, Dallaire L, Darling P \& Roy CC (1984) The composition of preterm milk in relation to the degree of prematurity. Am J Clin Nutr 40, 1042-1049.

Lonnerdal B, Forsum E \& Hambraeus L (1976) A longitudinal study of the protein, nitrogen, and lactose contents of human milk from Swedish well nourished mothers. Am J Clin Nutr 29, 1127-1133.

Lovelady CA, Meredith CN, McCrory MA, Nommsen LA, Joseph LJ \& Dewey KG (1993) Energy expenditure in lactating women: a comparison of doubly-labelled water and heart-rate monitoring methods. Am J Clin Nutr 57, 512-518.

Lucas A, Ewing G, Roberts SB \& Coward WA (1987) How much energy does the breast-fed infant consume and expend? Br Med J 295, 75-77.

Manson WG \& Weaver LT (1997) Fat digestion in the neonate. Arch Dis Child 76, F206-F211.

Matheny RJ \& Picciano MF (1985) Assessment of abbreviated techniques for determination of milk volume intake of the human milk fed infant. J Pediatr Gastroenterol Nutr 4, 808-812. 
Michaelsen KF, Larsen PS, Thomsen BL \& Samuelson G (1994) The Copenhagen Cohort Study on Infant Nutrition and Growth. Am J Clin Nutr 59, 600-611.

Michaelsen KF, Weaver LT, Branca F \& Robertson A (2000) Feeding and Nutrition of Infants and Young Children. WHO Regional Publications Series no. 87. Geneva: WHO.

Mitoulas LR, Kent JC, Cox DB, Owens RA, Sherriff JL \& Hartmann PE (2002) Variation in fat, lactose and protein in human milk over 24 hours and throughout the first year of lactation. $\mathrm{Br} \mathrm{J} \mathrm{Nutr}$ 88, 29-37.

Motil KJ, Sheng HP, Montandon CM \& Wong WW (1997) Human milk protein does not limit growth of exclusively breast-fed infants. $J$ Pediatr Gastroenterol Nutr 24, 10-17.

Neville MC, Keller R, Seacat J, Neifert M, Casey C, Allen J \& Archer P (1988) Studies in human lactation: milk volumes in lactating women during the onset of lactation and full lactation. Am J Clin Nutr 48, 1375-1386.

Neville MC \& Rasbach JO (1988) Is maternal milk production limiting for infant growth during the first year of life in breast-fed infants? In Human Lactation. III. The Effects of Human Milk on the Recipient Infant, pp. 123-133 [AS Goldman, editor]. New York: Plenum Press.

Nommsen LA, Lovelady CA, Heinig MJ, Lonnerdal B \& Dewey KG (1991) Determinants of the energy, protein, lipid, and lactose concentrations in human milk during the first twelve months of lactation. Am J Clin Nutr 53, 457-465.

Pao EM, Himes JM \& Roche AF (1980) Milk intakes and feeding patterns of breast-fed infants. J Am Diet Assoc 77, 540-545.

Paul AA, Cole TJ \& Whitehead RG (1988) Studies in lactation. J Hum Nutr Diet 1, 437-450.

Picciano MF, Calkins EJ, Garrick JR \& Deering RH (1981) Milk and mineral intakes of breast-fed infants. Acta Paediatr 70, 189-194.

Prentice AM, Paul AA, Prentice A, Black A, Cole TJ \& Whitehead RG (1986) Cross-cultural differences in lactational performance. In Human Lactation. II. Maternal and Environmental Factors, pp. 121-133 [M Hamosh and AS Goldman, editors]. New York: Plenum Press.

Sadurskis A, Kabir N, Wager J \& Forsum E (1988) Energy metabolism, body composition, and milk production in healthy Swedish women during lactation. Am J Clin Nutr 48, 44-49.

Salmenpera L, Perheentupa J \& Siimes MA (1985) Exclusively breast-fed healthy infants grow slower than reference infants. Pediatr Res 19, 307-312.
Scanlon KS, Alexander MP, Serdula MK, Davis MK \& Bowman BA (2002) Assessment of infant feeding: the validity of measuring milk intake. Nutrition 60, 235-251.

Southgate DAT \& Barrett IM (1966) The intake and excretion of calorific constituents of milk by babies. Br J Nutr 20, 363-372.

Southgate DAT \& Durnin JVGA (1970) Calorie conversion factors: an experimental reassessment of the factors used in the calculation of the energy value of human diets. Br J Nutr 24, 517-535.

Stroup DF, Berlin JA, Morton SC, Olkin I, Williamson GD, Rennie D, Moher D, Becker BJ, Sipe TA \& Thacker SB (2000) Meta-analysis of Observational Studies in Epidemiology (MOOSE) Group. Metaanalysis of observational studies in epidemiology: a proposal for reporting. JAMA 283, 2008-2012.

Stuff JE, Garza C, Boutte C, Fraley JK, Smith EO, Klein ER \& Nichols BL (1986) Sources of variance in milk and caloric intakes in breastfed infants. Am J Clin Nutr 43, 361-366.

Stuff JE \& Nichols BL (1989) Nutrient intake and growth performance of older infants fed human milk. J Pediatr 115, 959-968.

van Raaij JM, Schonk CM, Vermat-Miedema SH, Peek ME \& Hautvast JG (1991) Energy cost of lactation and energy balance of well nourished lactating women. Am J Clin Nutr 53, 612-619.

Wells JC (1994) Energy metabolism in breast-fed and formula-fed infants. PhD Thesis, University of Cambridge.

Whitehead RG \& Paul AA (1981) Infant growth and human milk requirements. Lancet i, 161-163.

Whitehead RG \& Paul AA (2000) Long-term adequacy of exclusive breast-feeding: how scientific research has led to revised opinions. Proc Nutr Soc 59, 17-23.

Whitehead RG, Paul AA, Black AE \& Wiles SJ (1981) Recommended dietary amounts for pregnancy and lactation in the UK. Food Nutr Bull Suppl 5, 259-265.

World Health Organization (1985) The Quantity and Quality of Breastmilk. Collaborative Study on Breastfeeding. Geneva: WHO.

World Health Organization (1995) The World Health Organisation Infant Feeding Recommendation. WHO Weekly Epidemiological Recommendations 17, 117-120.

Wood CS, Isaacs PC, Jensen M \& Hilton HG (1988) Exclusively breastfed infants: growth and caloric intake. Pediatr Nurs 14, 117-124.

Zoppi G, Andreotti G, Pajno-Ferrara F, Njai DM \& Garburro D (1972) Exocrine pancreas function in premature and full-term neonates. Pediatr Res 6, 880-886. 